\title{
Campanhas sanitárias como instrumentos da educação em saúde no Brasil: algumas reflexões para uma educação popular em saúde
}

\author{
Jefferson Silva Costa \\ Professor IA na Escola Técnica Ariano Vilar Suassuna da Rede Estadual de Pernambuco \\ Mestre em Ensino das Ciências pela Universidade Federal Rural de Pernambuco \\ $\bowtie$ jhefsilva.bio@gmail.com
}

\author{
Ana Maria dos Anjos Carmeiro-Leão \\ Professora Associada IV no Departamento de Morfologia e Fisiologia Animal e do Programa de Pós- \\ Graduação em Ensino das Ciências da Universidade Federal Rural de Pernambuco \\ Doutora em Ciências (Bioquímica) na Universidade Federal do Paraná
}

\begin{abstract}
Resumo:
No Brasil, o embrião do que é conhecido na atualidade por "Educação em Saúde" surge apenas na segunda metade do século XIX, após a chegada da família real portuguesa. Apesar disso, as campanhas sanitárias, definidas como publicidades que objetivam à orientação para execução de práticas de cuidado com a propria saúde, portanto instrumentos essenciais da Educação em Saúde, surgem apenas no começo do século XX, pautadas em um modelo coercitivo e fiscalizador. Com o passar das décadas, a utilização de campanhas sanitárias como instrumentos da Educação em Saúde foi tendo seus objetivos, publico-alvo e espaços de atuação modificados. Dessa forma, a veiculação desse tipo de campanha, da maneira como ocorre hoje, é fruto de um processo histórico que se entrelaça com os modelos de saúde e educação defendidos em cada época da história brasileira. Na atualidade, é defendido um modelo de Educação em Saúde mais dialógico e inclusivo, denominado de Educação Popular em Saúde, sendo necessário aplicar esse modelo para os instrumentos que compõem as campanhas sanitárias. Diante disto, ficou evidente a necessidade de refletir sobre a utilização, produção e mensagens veiculadas em campanhas sanitárias para compreender a necessidade desse material caminhar, de fato, para uma Educação Popular em Saúde.
\end{abstract}

Palavras-chave: Impressos para Educação em Saúde, Educação Popular em Saúde, Campanhas Sanitárias.

\section{Health campaigns as instruments of health education in Brazil: some reflections for Popular Education in Health}

\begin{abstract}
:
In Brazil, the embryo of what is known today as "Health Education" appears only in the second half of the 19th century, after the arrival of the Portuguese royal family. In spite of this, health campaigns, defined as advertisements that aim to guide the implementation of care practices with their own health, therefore essential instruments of Health Education, only appeared in the beginning of the 20th century, guided by a coercive and supervisory model. Over the decades, the use of health campaigns as instruments of Health Education has had its objectives, target audience and operating spaces modified. Thus, the propagation of this type of campaign, as it occurs today, is the result of a historical process that is intertwined with the health and education models defended at each time in Brazilian history. Currently, a more dialogical and inclusive model of Health Education, called Popular Education in Health, is advocated, and it is necessary to apply this model to the instruments that make up health campaigns. Given this, it became evident the need to reflect on the use, production and
\end{abstract}


messages conveyed in health campaigns to understand the need for this material to, in fact, move towards Popular Education in Health.

Keywords: Health Education Forms, Popular Health Education, Health Campaigns.

\section{Campañas de salud como instrumentos de educación sanitaria en Brasil: algunas reflexiones para la educación sanitaria popular}

\section{Resumen:}

En Brasil, el embrión de lo que hoy se conoce como "Educación para la salud" aparece solo en la segunda mitad del siglo XIX, después de la llegada de la familia real portuguesa. A pesar de esto, las campañas de salud, definidas como anuncios que tienen como objetivo guiar la implementación de prácticas de atención con su propia salud, por lo tanto, instrumentos esenciales de Educación para la Salud, solo aparecieron a principios del siglo XX, guiados por un modelo coercitivo y de supervisión. A lo largo de las décadas, el uso de campañas de salud como instrumentos de Educación para la Salud ha modificado sus objetivos, público objetivo y espacios operativos. Por lo tanto, la transmisión de este tipo de campaña, como ocurre hoy, es el resultado de un proceso histórico que se entrelaza con los modelos de salud y educación defendidos en cada época de la historia brasileña. Actualmente, se aboga por un modelo más dialógico e inclusivo de Educación para la Salud, llamado Educación Popular en Salud, y es necesario aplicar este modelo a los instrumentos que componen las campañas de salud. En vista de esto, se hizo evidente la necesidad de reflexionar sobre el uso, la producción y los mensajes transmitidos en las campañas de salud para comprender la necesidad de este material para, de hecho, avanzar hacia la Educación Popular en Salud.

Palabras clave: Formularios de educación en salud, educación popular en salud, campañas de salud.

\section{CONSIDERAÇÕES INTRODUTÓRIAS}

Campanhas Sanitárias são aquelas que orientam para o cuidado com a própria saúde ao invés do incentivo ao consumo (ROCHA e FELTES, 2016), e estão pautadas em um modelo de saúde do início do século XX, denominado de "Sanitarista Campanhista".

Desde então, as funções das campanhas sanitárias no processo educativo em saúde sofreram modificações, passando, inclusive, a terem alguns de seus impressos utilizados no ambiente escolar formal a partir do entendimento de que o professor deve desempenhar também o papel de "sujeito educador em saúde", além de todo o resto da população (SILVA, C. et al., 2010).

Do ponto de vista legal, os PCNEM+ (Parâmetros Curriculares Nacionais do Ensino Médio Mais) da área de Ciências da Natureza (BRASIL, 2002), ratificam a necessidade de serem trabalhados diversos tipos de textos informativos e midiáticos no processo escolar, corroborando o entendimento do professor como sujeito educador de campanhas sanitárias em sala de aula. 
Com isso, as campanhas sanitárias tornaram-se cada vez mais frequentes no ambiente educacional, sobretudo as que visam a combater doenças epidêmicas e/ou endêmicas que possuem como vetores organismos vivos, especialmente dípteros ${ }^{1}$, que podem adentrar de forma quase imperceptível na vida de praticamente todos os cidadãos, em função de seu tamanho e mobilidade. Neste sentido, é necessário refletir sobre o processo histórico das campanhas sanitárias atrelado a Educação em Saúde e ao próprio conceito de saúde no Brasil, especialmente porque "a relação entre a educação, saúde e suas práticas é condicionada por dimensões estruturais complexas que precisam de uma análise histórica para sua maior compreensão." (SILVA, 2010, p. 2540).

Além disso, na concepção de Maciel (2009), os conceitos e objetivos da Educação em Saúde, com o passar do tempo, foram igualmente influenciados pelas modificações nos processos pedagógicos de ensino e aprendizagem da educação escolar formal.

Apesar das mudanças, as campanhas sanitárias sempre se fizeram presentes, permeando as diversas concepções de saúde e oferecendo subsídios para a sua promoção e/ou combate a doenças; termina, deste modo, por fortalecer a necessidade de um entrelace entre as campanhas sanitárias e o histórico da Educação em Saúde. Dessa forma, adentrar nos meandros históricos das campanhas sanitárias e entender seu processo de estabelecimento e suas características, implica discutir sobre a história da Educação em Saúde no Brasil.

Este ponto é reforçado pelas palavras de Silva, C. et al. (2010), ao alegar que

no plano histórico, a sucessão de modelos de educação aplicados à área da saúde pública não significa uma sequência evolutiva; antes, é uma descrição da prática dominante em certos períodos em relação aos problemas de saúde destacados para intervenção, visando à manutenção da hegemonia da classe dominante. (p. 2540).

Ou seja, a análise histórica não pode ser feita em uma perspectiva de modificação progressiva dos modelos de Educação em Saúde, mas sim no sentido de correlacionar cada modelo ao contexto histórico, visando a compreender sua complexidade, sobretudo se considerarmos que alguns métodos, a exemplo das campanhas sanitárias, sempre estiveram

\footnotetext{
${ }^{1}$ É uma ordem de organismos pertencente à classe Insecta, filo Arthropoda e Reino Animalia, na qual estão inclusos as moscas e os mosquitos em geral.
} 
presentes, havendo mudança apenas na forma de sua aplicabilidade. É isto que tentamos fazer em nosso próximo tópico.

\section{HISTÓRICO DAS CAMPANHAS SANITÁRIAS COMO INSTRUMENTOS DA EDUCAÇÃO EM SAÚDE NO BRASIL}

Apenas no século XIX, em função da mudança da família real portuguesa para o Brasil em 1808, é que se começou a pensar em pedagogias higiênicas para o Brasil Colônia com o objetivo de educar as famílias da elite (SILVA et al., 2010), através da fundação, por Dom João VI, do Colégio Médico-Cirúrgico no Real Hospital Militar da Cidade de Salvador, na Bahia; e por meio da criação, em novembro do mesmo ano, da Escola de Cirurgia do Rio de Janeiro, anexa ao Real Hospital Militar (POLIGNANO, 2001).

Diante da despreocupação do Estado para com questões de saúde, e das péssimas condições sanitárias e socioeconômicas em que a população vivia, iniciam-se epidemias de peste, febre amarela e varíola em território brasileiro no final do século XIX e início do século XX (MACIEL, 2009; PELICIONI e PELICIONI, 2007; SILVA et al., 2010). Nesse contexto, o Estado se viu obrigado a intervir sistematicamente em modelos de Educação em Saúde de forma ampliada às classes populares, visando combater a evasão de navios mercantes dos portos brasileiros, que prejudicava o modelo agrário-exportador da época (MACIEL, 2009; SILVA et al., 2010).

Todavia, este modelo ampliado de Educação em Saúde, denominado de "Educação Sanitária” (MACIEL, 2009, p. 774), era coercitivo para as camadas populares, que encontravam algoz na chamada "polícia sanitária", criada para coibir, fiscalizar e manter o bem-estar, desconsiderando a relação doença/ambiente. Neste período, a ignorância dos populares era tida como a causadora das epidemias da época (SILVA et al., 2010). Dessa forma, o processo de ampliação não visava a persuadir ou sensibilizar, mas sim inibir práticas tidas como "prejudiciais", caracterizando a saúde e o bem-estar como um dever ao invés de um direito.

Além disso, na leitura de Galvão (2009), esse modelo objetivava apenas combater doenças epidêmicas que atacassem de forma indiscriminada as diversas classes sociais. 0 autor cita o exemplo da tuberculose, que se constituía como um problema real de setores mais 
insalubres da sociedade. Contudo, como a taxa de mortalidade elevada não atingia as elites, a doença não era considerada um problema pelo Estado brasileiro da época.

Silva et al. (2010) destacam ainda que no período que compreende o final do século XIX e início do XX eram distribuídos à população os chamados "conselhos ao povo" (p. 2541), que seriam folhetos avulsos sobre os meios de evitar doenças, constituindo práticas educativas marginais. Os autores salientam que o objetivo não era educar a população, mas sim utilizar o discurso de que instrumentos de convencimento haviam sido utilizados antes de o Estado ser "obrigado" a agir de forma coercitiva. Este modelo, implementado oficialmente em nível nacional por Oswaldo Cruz em 1902, ficou conhecido como "sanitarismo campanhista" (POLIGNANO, 2001), cujo papel principal do educador (imbuído à polícia sanitária, conforme quadro 1) era de controlar e fiscalizar a população.

Este "campanhismo" de Cruz pode ser considerado um marco para a implementação das campanhas de combate às doenças no Brasil. Contudo, em função das características históricas da época, as campanhas contra a febre amarela, em 1903, e contra a peste bubônica, em 1904, consistiram, muitas vezes, na invasão dos domicílios para extermínio dos vetores biológicos, destruição de prédios de habitações coletivas, exigência de modificações arquitetônicas onerosas nas moradias, internações forçadas e interdições (GALVÃO, 2009; MACIEL, 2009). Ou seja, as campanhas sanitárias implementadas por Cruz não tinham como objetivo persuadir a população, mas sim anteceder a ação da polícia sanitária, conforme quadro 1, o que causou amplo descontentamento nas classes populares.

A última, e mais amplamente conhecida, campanha executada por Oswaldo Cruz no Brasil com este modelo foi a de vacinação contra varíola, executada a partir da promulgação de uma lei, em novembro de 1904, que tornava a vacina obrigatória em todo o território nacional (MACIEL, 2009; SILVA et al., 2010). A lei causou ampla revolta de setores diversos da sociedade, desembocando na conhecida Revolta da Vacina.

Fica evidente que a educação/sensibilização não foi o objetivo das campanhas sanitárias implementadas neste período, conforme já concluíram Pelicioni e Pelicioni (2007). A participação de profissionais da educação nas campanhas, assim como um processo que objetivasse educar/sensibilizar a sociedade civil com mais diálogo por parte das forças políticas poderiam ter possibilitado investiduras mais exitosas para as camadas populares no período. 
Apesar da publicação do livro "Os Sertões”, de Euclides da Cunha, em 1902 ter causado ampla indignação nos círculos de intelectuais brasileiros, em função do relato de miséria e descaso com o Sertão nordestino que a obra trouxe, somente em 1918, quando Monteiro Lobato publica seu livro de contos "Urupês", a situação de descaso com a saúde do sertanejo ganha repercussão, desconstruindo o perfil do "caipira" preguiçoso que não faz nada para modificar sua realidade (SILVA et al., 2010).

Falkenberg et al. (2014) destacam que o motivo da repercussão da obra de Lobato na época foi o personagem Jeca Tatu, que era um trabalhador rural do Vale do Paraíba - SP, que sofria de ancilostomose. O personagem servia para denunciar as precárias condições de vida da população em relação, sobretudo, à falta de assistência à saúde.

Com isso, o personagem de Jeca Tatu serviu para mostrar que a problemática brasileira sertaneja não estava associada à raça, mas sim às doenças que acometiam a população, tornando-a preguiçosa e sem iniciativa (SILVA, C. et al., 2010).

Além disso, na época eram comuns, conforme relatam Falkenberg et al. (2014), que campanhas sanitárias utilizassem a figura de Jeca Tatu "indicando que as origens dos problemas de saúde eram de responsabilidade individual, não contextualizando os problemas sanitários de forma crítica a partir de mudanças coletivas." (p. 849), servindo apenas para reforçar o modelo sanitarista campanhista, sem apresentar iniciativas educacionais profícuas.

Apenas a partir da década de 1920, quando Carlos Chagas reestrutura o Departamento Nacional de Saúde Pública (DNSP), é oferecido espaço para os educadores na Educação em Saúde (quadro 1), ficando ao seu encargo o papel de divulgar e convencer a população brasileira a adotar certos padrões de comportamento tidos como ideais para a manutenção da saúde.

Nesta época, começa a ser designada formalmente uma "educação sanitária" e a propaganda, segundo Polignano (2001), começa a constituir as práticas rotineiras de ação do DNSP, sendo esta a primeira vez, na história do Brasil, em que a Prevenção assume lugar de destaque nos processos de Educação em Saúde e nas campanhas sanitárias veiculadas.

De acordo com Silva et al. (2010, p. 2542), a estrutura de educação sanitária que começou a vigorar a partir de 1920 "veio retirar a autoridade de polícia sanitária e as ações 
de educação em saúde passaram a se desenvolver pelos educadores sanitários e professoras, que eram treinados para exercerem a função de educar a população escolar". Dessa forma é possível observar que as revoltas (tanto populares como literárias) e a mudança de rumos do DNSP ocasionaram uma estruturação primária do que viria a ser denominado Educação em Saúde nas décadas seguintes, com um enfoque maior na persuasão e menor na coação.

Entretanto, no entendimento de Vasconcellos (2001), as ações desses educadores ainda se constituíam da imposição normativa de comportamentos considerados pelas elites como adequados para a promoção da saúde. Ou seja, nesta época mantém-se o modelo de Educação em Saúde, recorrente nos anos de 1900, que o autor denominou de "toca boiada" (p. 123).

Contudo, na concepção de Vasconcelos (2001), há uma diferença entre o modelo de "toca boiada" adotado em 1900 e o de 1920: se com Cruz a condução da boiada (público em geral) era realizada exclusivamente por intermédio do ferrão (o medo e a ameaça); com Chagas, o berrante (a palavra do educador subsidiada pelas peças de campanhas sanitárias) passou a ser também considerado um instrumento essencial. 
Quadro 1 - Sistematização sobre a trajetória da Educação em Saúde no Brasil e o papel das campanhas sanitárias em diferentes períodos.

\begin{tabular}{|c|c|c|c|c|c|}
\hline COMPONENTES & ATÉ ANOS 1920 & ANOS 1920 & ANOS 1950 & ANOS 1960 E 1970 & A PARTIR DOS ANOS 1980 \\
\hline $\begin{array}{l}\text { Designação das práticas } \\
\text { educativas em saúde }\end{array}$ & Não configurada. & Educação sanitária. & Educação para a Saúde. & $\begin{array}{l}\text { Educação em Saúde pública ou } \\
\text { Educação em Saúde. }\end{array}$ & $\begin{array}{l}\text { Educação em Saúde e Educação } \\
\text { Popular em Saúde. }\end{array}$ \\
\hline $\begin{array}{c}\text { Evento (s) que } \\
\text { influenciou (aram) a } \\
\text { metodologia aplicada } \\
\text { em tais práticas }\end{array}$ & $\begin{array}{l}\text { Relatório Flexner. } \\
\text { Bacteriologia de } \\
\text { Pasteur. }\end{array}$ & \begin{tabular}{|c|} 
Primeira reforma \\
sanitária brasileira. \\
Criação do Ministério da \\
Educação e Saúde Pública \\
\end{tabular} & \begin{tabular}{|c|} 
Chega ao Brasil a Fundação \\
FSESP (Fundação de Serviços \\
Especiais de Saúde Pública) e \\
criação do Ministério da Saúde \\
\end{tabular} & $\begin{array}{c}\text { Golpe militar no Brasil, } \\
\text { Conferência de Alma-Ata e } \\
\text { projetos de medicina } \\
\text { comunitária. }\end{array}$ & $\begin{array}{l}\text { VIII Conferência Nacional de } \\
\text { Saúde e a Constituição Cidadã. }\end{array}$ \\
\hline $\begin{array}{l}\text { Local ou espaços de } \\
\text { atuação }\end{array}$ & $\begin{array}{l}\text { Residências e locais } \\
\text { públicos. }\end{array}$ & $\begin{array}{c}\text { Centros de saúde, escolas } \\
\text { e lares. }\end{array}$ & $\begin{array}{l}\text { Escolas, locais de trabalho e } \\
\text { comunidades rurais. }\end{array}$ & Serviços de saúde e escolas. & $\begin{array}{c}\text { UBS (Unidade Básica de Saúde), } \\
\text { escolas e espaços } \\
\text { comunitários. }\end{array}$ \\
\hline População- alvo & Elite urbana. & $\begin{array}{l}\text { Famílias e } \\
\text { escolares. }\end{array}$ & $\begin{array}{c}\text { População urbana e rural de } \\
\text { todas as idades. }\end{array}$ & Escolares e grupos específicos. & Toda a população. \\
\hline Quem era o educador & Polícia sanitária. & $\begin{array}{l}\text { Educador sanitário e } \\
\text { professoras. }\end{array}$ & $\begin{array}{l}\text { Educador sanitário e } \\
\text { profissionais de saúde. }\end{array}$ & $\begin{array}{l}\text { Equipes de saúde } \\
\text { multiprofissionais. }\end{array}$ & $\begin{array}{l}\text { Todos envolvidos, incluindo a } \\
\text { população. }\end{array}$ \\
\hline $\begin{array}{l}\text { Atribuições do } \\
\text { educador }\end{array}$ & Fiscalização. & $\begin{array}{c}\text { Divulgar o saber médico } \\
\text { e convencer as camadas } \\
\text { populares a seguirem } \\
\text { padrões de } \\
\text { comportamento. }\end{array}$ & $\begin{array}{c}\text { Práticas de intervenção social } \\
\text { para modificar o } \\
\text { comportamento social e gerar } \\
\text { mudanças culturais. }\end{array}$ & $\begin{array}{l}\text { Capacitar o educando para o } \\
\text { autocuidado. }\end{array}$ & $\begin{array}{l}\text { Buscar, junto com a população, } \\
\text { propostas de solução dos } \\
\text { problemas na saúde. }\end{array}$ \\
\hline Papel do educador & Controlador. & $\begin{array}{l}\text { Divulgador e } \\
\text { comunicador. }\end{array}$ & Interventor. & Treinador. & Mediador. \\
\hline $\begin{array}{c}\text { Atividades } \\
\text { desenvolvidas pelos } \\
\text { profissionais da } \\
\text { educação em saúde }\end{array}$ & \begin{tabular}{|} 
Propaganda sanitária \\
e \\
Fiscalização \\
sanitária.
\end{tabular} & $\begin{array}{c}\text { Palestras, conferências e } \\
\text { produção de } \\
\text { impressos. }\end{array}$ & $\begin{array}{l}\text { Educação de grupos e } \\
\text { trabalhos em equipe. } \\
\text { Incentivo à participação } \\
\text { comunitária para suprir } \\
\text { carências do governo. }\end{array}$ & \begin{tabular}{|c|} 
Metodologia centrada no \\
educador ou profissional, que \\
passa informaç̃̃es sobre o \\
autocuidado à população.
\end{tabular} & $\begin{array}{l}\text { Educação tradicional é ainda } \\
\text { hegemônica, mas a metodologia } \\
\text { participativa ganha espaço nas } \\
\text { universidades e nas políticas de } \\
\text { saúde. }\end{array}$ \\
\hline $\begin{array}{l}\text { Papel das campanhas } \\
\text { sanitárias }\end{array}$ & $\begin{array}{c}\text { Anteceder a ação da } \\
\text { polícia sanitária. }\end{array}$ & $\begin{array}{l}\text { Principal veículo de } \\
\text { informação }\end{array}$ & $\begin{array}{l}\text { É apenas mais um veículo de } \\
\text { informação }\end{array}$ & Informar conjunto de normas. & $\begin{array}{l}\text { Mediar as relações educador- } \\
\text { educandos. }\end{array}$ \\
\hline
\end{tabular}

Fonte: Silva, C. et al. (2010) com adaptações do autor.

Revista SUSTINERE, Rio de Janeiro, v. 9, suplemento 2, p. 333-351, setembro, 2021 
Um avanço a ser pontuado neste período diz respeito à inauguração de Postos de Profilaxia Rural (PPR), no interior de mais de onze estado, que centralizaram as ações de Educação em Saúde e institucionalizaram essas práticas (GALVÃo, 2009).

Apesar de reconhecer esses avanços, Silva et al. (2010) ressaltam que, embora haja a difusão dos PPR no interior do país, o enfoque principal, da então “Educação Sanitária”, eram crianças e adolescentes, especialmente porque o período coincide com a chamada "Escola Nova", que atribuiu ao educando o foco do processo de ensino e aprendizagem. Os autores sublinham ainda que o processo de sensibilização neste modelo de Educação em Saúde era sustentado pelo ideário positivista, uma vez que os educadores eram treinados para repetir os mesmos discursos e utilizar os mesmos materiais propagandísticos onde quer que estivessem, o que os afastava dos sujeitos a serem educados. Com isso, este modelo ainda se consolida muito mais como um levantador de murros, dificultando o processo de ensino e aprendizagem na Educação em Saúde.

Na década de 1930 a Era Vargas se caracterizou, de acordo com Maciel (2009), pela construção de Centros de Saúde cujo o objetivo era difundir noções de saúde e higiene individual. Esse modelo visou superar seu antecessor, que lograva muita importância aos agentes etiológicos e quase nenhuma aos fatores ambientais que poderiam desencadear doenças (SILVA et al., 2010).

Em vias de intensificar o combate as doenças infecciosas e parasitárias, "as ações educativas em saúde ficam restritas a programas e serviços destinados a populações à margem do jogo político central" (VASCONCELOS, 2015, p. 26), com isso, as campanhas sanitárias desta época eram voltadas para as classes mais populares e para programas especiais, tais como o materno infantil e o pronto-socorro (SILVA et al., 2010). Dessa forma, as campanhas sanitárias possuíam o papel de comunicar formas de prevenir doenças, revivendo o modelo sanitarista campanhista nos anos 1920.

Nos anos de 1950, conforme quadro 1, a chamada "Educação Sanitária" oferece lugar para uma "Educação para a Saúde", que possui como marco principal a criação da FSESP (Fundação de Serviço Especial de Saúde Pública), constituindo-se como um propulsor para os avanços das instituições de saúde brasileiras, uma vez que trouxe novas tecnologias de prevenção para o Brasil. 
Além disso, inicia-se o modelo de "Sanitarismo Desenvolvimentista" (PELICIONI e PELICIONI, 2007), que teve como um dos principais mentores o médico sanitarista Mário Magalhães da Silveira. Na concepção de Escorel (2015), este novo modelo associa desenvolvimento à saúde, surgindo como uma crítica ao Sanitarismo Campanhista e favorecendo ambientes profícuos para experiências que viessem a propiciar o desenvolvimento social.

Dessa forma, para alcançar sucesso nas políticas de saúde e de Educação em Saúde era preciso desenvolver o Brasil e sua população, do ponto de vista econômico e social, rompendo com a ideia de que apenas uma parcela da população poderia ser educada. Além disso, a concepção de autossuficiência das campanhas sanitárias para resolver os problemas das epidemias também é abandonada. Ou seja, neste período as campanhas sanitárias perdem a posição majoritária de comunicação com a população.

A partir disso, surge outro aspecto a ser destacado: uma proposta de participação popular na saúde, que, segundo Silva et al. (2010), surge para tentar canalizar e mobilizar a energia da população para superar a marginalidade em que se encontravam certas parcelas da sociedade neste período.

Com o novo modelo surgem inovações metodológicas de ensino e aprendizagem incorporadas à Educação para a Saúde, tais como: "educação de grupos, os recursos audiovisuais e o desenvolvimento e organização de comunidades, desencadeando ideias de participação e mobilização de indivíduos nas ações de saúde, contrariando a política centralizadora e paternalista do Estado como um todo. " (SILVA et al., 2010, p. 2544).

Polignano (2001) sublinha que este período foi marcado por: escassez de recursos financeiros e de pessoal entre diversos órgãos e setores criados para promoção e fiscalização da saúde; conflitos de jurisdição e gestão entre a União, Estados e Municípios; e superposição de funções e atividades de alguns órgãos. Ainda de acordo com o autor, todos esses entraves "fizeram com que a maioria das ações de saúde pública no Estado [...] se reduzissem a meros aspectos normativos, sem efetivação no campo prático de soluções para os grandes problemas sanitários existentes no país naquela época." (p.12).

Dessa forma, é possível que o processo de convite à participação popular tenha ocorrido não pelo interesse em fornecer à população assento cativo nas deliberações sobre a 
então denominada Educação para a Saúde, mas sim para utilizar a mão de obra popular naquilo que o Estado se mostrava ineficiente: promover a saúde. Este entendimento é fortalecido por Silva et al. (2010), quando os autores afirmam que muito embora este período seja marcado pela ampliação de espaços físicos dos serviços, capacitação de diversos voluntários de saúde e programas de participação comunitária para obras de saneamento, a medicina empregada era de cunho simplista e não contribuía para redução do fosso cultural e social para as camadas populares a quem se destinava.

Valla (2006) critica este "modelo de participação popular". Na concepção deste autor, o processo de participação popular só é efetivo se conferir poder de decisão e participação política de entidades da sociedade civil organizada em instituições, agências, serviços e/ou órgãos estatais que atuem nas políticas sociais, conferindo a estas entidades a oportunidade de disputar o controle e o destino das verbas públicas.

Entretanto, para Silva et al. (2010), é preciso pontuar que, embora a concepção de participação popular tenha sido manipulada pelo Estado neste período, a Educação para a Saúde passou a ser oferecida a toda a população. Agora, não apenas as crianças e adolescentes eram considerados os únicos capazes de serem educados, tendo sido plantada uma semente do que viria ser uma Educação Popular em Saúde.

Em 1964, o Brasil sofre um golpe militar, que resultou na piora dos serviços de saúde para as camadas mais carentes da população (SILVA et al., 2010), ocasionando o recrudescimento de algumas enfermidades, tais como: tuberculose, malária e doença de Chagas (MACIEL, 2009). Além disso, a política de saúde desta época perpassou um sistema de avanço dos serviços de saúde privados, notadamente hospitais, que passaram a ser responsáveis pela atenção à saúde (PELICIONI e PELICIONI, 2007; VASCONCELOS, 2015) e nos quais as práticas educativas não tinham espaço (VASCONCELOS, 2015). Com isso, as camadas populares do país foram forçadas a coexistir com as doenças infecciosas, com o sofrimento físico por elas ocasionado e sem acesso a políticas eficientes de saúde pública.

A partir daí emerge uma lógica puramente tecnocrata dos grupos de educadores (neste período compostos por multiprofissionais) que atuavam na então denominada "Educação em Saúde", pressupondo um entendimento de que lhes competia o treinamento do educando (quadro 1) para o autocuidado (SILVA et al., 2010) - Uma lógica puramente 
transmissional e positivista, similar àquela adotada na década de 1920. Nesse sentido, as campanhas sanitárias agora existiam como um conjunto de normas a serem seguidas.

A partir da década de 1970, o Estado brasileiro se viu diante de uma possibilidade de quebra da estabilidade social, sendo forçado a ser mais atencioso com problemas de cunho social da população, dentre eles a saúde (POLIGNANO, 2001). A partir desta década se torna obrigatória a Educação em Saúde nos ensinos médio e fundamental ${ }^{2}$, em função do artigo 7을 da lei número 5.692/71, “com o objetivo de estimular o conhecimento e a prática da saúde básica e da higiene nos escolares" (SILVA et al., 2010, p. 2545).

Nesta década criou-se também a SUCAM (Superintendência de Campanhas da Saúde Pública), que possuía como principal atribuição executar atividades que levassem à erradicação e o controle de endemias, sobretudo a campanha de erradicação da malária (POLIGNANO, 2001).

Apesar disso, eclodiram diversos movimentos populares em todo o país (PELICIONI e PELICIONI, 2007), incentivando especialistas em saúde, indignados com o modelo aplicado pelo regime militar, a desenvolverem trabalhos voltados para a dinâmica da realidade das classes mais populares (FALKENBERG et al., 2014; MACIEL, 2009; VASCONCELOS, 2015).

Segundo Vasconcelos (2001; 2015), esse movimento inovou a cultura no setor da Saúde brasileira em duas frentes intrinsecamente relacionadas: primeiro, implementou a construção de relações de trocas de saberes entre os educadores em saúde e as comunidades populares, desconstruindo a lógica transmissional positivista presente nas campanhas sanitárias da época; e segundo, como consequência do primeiro, rompeu com a dinâmica autoritária e normatizadora da Educação em Saúde.

Dessa forma, apesar do ambiente autoritário, houve um espaço propício para o surgimento de reflexões entre diversos setores da sociedade, principalmente especialistas encurralados nas Universidades, para construir um sistema de saúde que viesse a atender às necessidades da população. A partir desse entendimento, começam a ser

introduzidos no Brasil os princípios dos cuidados primários de saúde, baseados nas recomendações da Conferência de Alma-Ata (ROCHA, 1997), dando uma nova direção às políticas de saúde, enfatizando a participação

\footnotetext{
${ }^{2}$ Neste período essas fases escolares eram denominadas, respectivamente, de primeiro grau e segundo grau, optamos por adotar a nomenclatura atual no corpo do texto.
} 
comunitária, a cooperação entre diferentes setores da sociedade e os cuidados primários de saúde em seus fundamentos conceituais (OLIVEIRA, 1997; ROCHA, 2003). (SILVA, C. et al., 2010, p. 2545).

Para Pelicioni e Pelicioni (2007), embora a ditadura militar só tenha sido finalizada em 1985, esses movimentos constituem o início da redemocratização do Brasil, principalmente no tocante à participação da sociedade civil nas políticas de saúde no país.

Falkenberg et al. (2014) e Vasconcelos (2015) salientam que um dos principais influenciadores das modificações educacionais que estavam por acontecer foi o educador Paulo Freire, que em suas experiências defendia a necessidade de uma educação menos verticalizada e muito mais dialógica, ao que o educador e pesquisador denominou de Educação Popular. Estas concepções influenciaram diretamente na Educação em Saúde.

As experiências de Educação em Saúde com a participação popular começam a ser mais recorrentes, sendo denominada a partir dos anos 1980, conforme quadro 1, de "Educação Popular em Saúde" (MACIEL, 2009), atuando nas áreas rurais e nas periferias urbanas juntamente com a chamada "Medicina Comunitária"3 (SILVA, et al., 2010).

É importante destacar que

a educação popular em saúde tem uma concepção diferenciada da hegemônica da educação em saúde, [pois se] organiza a partir da aproximação com outros sujeitos no espaço comunitário, privilegiando os movimentos sociais locais, num entendimento de saúde como prática social e global e tendo como balizador ético-político os interesses das classes populares. Baseia-se no diálogo com os saberes prévios dos usuários dos serviços de saúde, seus saberes "populares”, e na análise crítica da realidade. (FALKENBERG et al., 2014, p. 849).

Ou seja, a ideia de uma Educação Popular em Saúde surge da necessidade de se construir um elo entre a educação técnico-científica e o saber popular, considerando as camadas populares como detentoras de um conhecimento sobre a sua realidade que os Educadores em Saúde deveriam compreender. A partir disso, o objetivo agora não é formar cidadãos polidos que ajam de acordo com um conjunto de normas predeterminadas, mas sim

${ }^{3}$ Para Vidal (1975, p. 11, tradução nossa), a medicina comunitária seria "o conjunto de ações intra e extrahospitalaris de medicina integrada que forma uma equipe de saúde com a participação ativa da comunidade". 
auxiliar as camadas populares na conquista de sua autonomia e de seus direitos (MACIEL, 2009), sendo a saúde um deles e as campanhas sanitárias um instrumento de mediação entre o sujeito educador e os sujeitos educandos.

Atualmente, tanto "Educação em Saúde" como "Educação Popular em Saúde" são termos corriqueiramente utilizados no Brasil para descrever práticas educativas em saúde. Entretanto, para Falkenberg et al. (2014), apesar das duas práticas possuírem os pressupostos teóricos similares de interação dialógica entre os profissionais, gestores e a população, constituindo um espaço que sirva para reflexão e tomada de autonomia individual e coletiva, as práticas de Educação em Saúde corriqueiramente abandonam por completo esses pressupostos.

Segundo Vasconcelos (2017), isso justifica o reforço dialógico que a Educação Popular em Saúde tem a oferecer nas práticas de Educação em Saúde, uma vez que na atualidade é fundamental um modelo que rompa com o entendimento de que as classes populares são "tabulas rasas" desprovidas de conhecimento, mas sim

[...] compostas de pessoas e grupos com uma intensa "busca de ser mais" (expressão muito usada por Paulo Freire), com significativos e surpreendentes saberes sobre como buscar a alegria e a saúde em suas condições concretas de existência e com grande criatividade para participar da construção de soluções para seus problemas. (VASCONCELOS, 2017, p. 21).

No entanto, no entendimento de Valla (2006), os documentos oficiais da federação, estados e municípios costumam adotar um tom difuso no tocante ao que seria a participação popular na Educação em Saúde. Na perspectiva do autor os governos brasileiros ainda agem de forma bastante autoritária com as camadas populares, decidindo unilateralmente a respeito de quais problemas de saúde pública merecem atenção, grau de investimento em cada epidemia e, por consequência, o tom das campanhas sanitárias, que terminam por conclamar a participação da comunidade no processo de erradicação de um determinado "mal" (epidemia em alta), através de um mutirão ${ }^{4}$. Ou seja, nos documentos oficiais, a

\footnotetext{
${ }^{4}$ Para Valla (2006) são exemplos de prática de mutirão a construção de postos de saúde, reformas de escolas, limpeza de ruas e outras atividades que seriam de obrigação estatal e a população é convidada a realizar em campanhas governamentais.
} 
participação popular na Educação em Saúde fica restrita às ações predeterminadas pelo Estado.

Silva et al. (2010) destacam que a prática de um mutirão, nos termos pontuados por Valla (2006), foge por completo aos pressupostos da Educação Popular em Saúde, uma vez que funciona apenas para o Estado utilizar mão de obra gratuita para execução de tarefas que estão ao seu encargo, de forma bem similar ao ocorrido na década de 1950.

Valla (2006) vai além ao defender que ao conclamar a população para exterminar um determinado vetor biológico de uma doença, através das campanhas sanitárias, os governos individualizam a questão. Ou seja, se o culpado direto pelo adoecimento é o vetor biológico, o indireto seria a população que não executou o conjunto de ações solicitadas nas campanhas. Isso é conhecido por "culpabilização da vítima, uma prática que permite esconder o mau funcionamento dos serviços públicos e o descompromisso dos governos. " (VALLA, 2006, p. 53, grifo nosso), que segue sendo cada vez mais comum em campanhas sanitárias do século XXI.

Nesse sentido, a demarcação de território da Educação Popular em Saúde, no sentido de fortalecer seus pressupostos e acabar com as pseudopráticas que se dizem populares, é muito mais que necessária, estendendo esse dever para as campanhas sanitárias, que devem ser um instrumento desse modelo de Educação em Saúde.

Essa preocupação é reforçada quando lembramos que muitas dessas campanhas podem ser utilizadas pelos professores, levadas pelos estudantes ou até mesmo indicadas por órgãos ligados aos Governos Federal, Estadual e/ou Municipal (Secretárias/Ministérios de Educação, Saúde, Meio Ambiente, entre outros) como fontes de informações. Caminhando nesta direção, Almeida-Júnior (2000) atenta para o fato de que devemos considerar esses recursos visuais como discursos informativos da sociedade, visto que eles podem ser responsáveis "por mecanismos de reitificação ${ }^{5}$ do sujeito educando, [e] devem ser considerados como modelo instituinte de realidades" (p.19).

Charaudeau (2013) pontua ainda que uma campanha sanitarista "visa a dissuadir os indivíduos, que vivem em sociedade, de manter um comportamento prejudicial à

${ }^{5}$ Reitificação é um termo utilizado pelo autor Almeida-Júnior (2000) para designar o processo de fazer um sujeito desenvolver um conjunto de condutas aceitáveis socialmente. 
coletividade, sendo necessária a adoção de outro comportamento" (p. 383). Essa concepção é reforçada por Joly (1996), quando a autora sublinha que as campanhas publicitárias, das quais fazem parte as campanhas sanitaristas, são com toda a certeza intencionais, e objetivam coerseduzir ${ }^{6} \mathrm{o}$ sujeito para adotar determinadas condutas e práticas.

Dessa forma, é preciso considerar as campanhas sanitárias como instrumentos que podem ser utilizados pelo professor durante a mediação da relação entre conhecimento e educando, a afim de promover a pretensa Educação Popular em Saúde que possibilite a construção da autonomia do sujeito, através do pensar sobre os modelos nelas propagados.

Este alerta torna-se ainda mais contundente quando consideramos os modelos comunicativos adotados nas campanhas sanitárias da atualidade. 0 estudo desenvolvido por Freitas e Rezende-Filho (2011) buscou analisar em artigos científicos nacionais, através de pesquisas de termos-chave ${ }^{7}$ no Scielo (Scientific Eletronic Library Online), modelos de comunicação de impressos utilizados como estratégia educativa na saúde. Dos onze artigos encontrados pelos autores, nove continham impressos de campanhas sanitárias que reforçam o modelo de que o sujeito a ser educado é apenas um consumidor das práticas ali presentes.

Além disso, é crucial ponderar como essas campanhas são utilizadas na Educação em Saúde. Pesquisas desenvolvidas por Sales (2008) e Souza et al. (2003) sinalizam a importância de que o educador em saúde não utilize uma campanha sanitária considerando o sujeito educando apenas como o "público-alvo", mas o compreenda como sujeito do conhecimento e assim incentive este sujeito não apenas a aplicar as informações nos materiais como também a promover alterações no sentido de aproximá-los de seu cotidiano. Em nosso entendimento a prática de incentivar o processo de adequação desses materiais é um passo para auxiliar o rompimento da lógica transmissional apontada como corriqueira no estudo de Freitas e Rezende-Filho (2011).

Claro que estes estudos simbolizam apenas um recorte de toda a amplitude de campanhas sanitárias veiculadas no cenário nacional, porém revela uma tendência

\footnotetext{
${ }^{6}$ Segundo Joly (1996), este seria um acrônimo entre as palavras "coerção" e "sedução", ao qual adaptamos para uma forma verbal não existente na língua portuguesa.

${ }^{7} \mathrm{O}$ descritor usado na pesquisa inicial foi "educação em saúde" combinado com unitermos (materiais didáticos, material educativo, material informativo, impressos, folhetos, cartazes, cartilhas educativas, e manuais de orientação); na segunda pesquisa foi utilizado o descritor "impressos", para uma busca mais precisa (FREITAS e REZENDE-FILHO, 2011).
} 
preocupante desses instrumentos, fortalecendo a preocupação a respeito da necessidade de uma Educação Popular em Saúde no processo de utilização e construção desse recurso.

Apesar disso, faz-se necessário determinar o termo "Educação em Saúde" como majoritário, sobretudo em função das recomendações oficiais da Biblioteca Virtual em Saúde (BVS), vinculada ao Ministério da Saúde brasileiro, conforme Falkenberg et al. (2014). Mas é preciso salientar a compreensão de que a usabilidade do termo não implica no desconhecimento dos objetivos defendidos pela Educação Popular em Saúde, pois, segundo Vasconcelos (2015), a Educação Popular deve ser entendida como referencial teórico que deve permear a Educação em Saúde, antes de ser compreendida como modelo independente. Ou seja, a utilização de campanhas sanitárias, como instrumentos Educativos, deve ser respaldada pelas premissas do diálogo entre sujeito educador e sujeito educando, oportunizando trocas de saberes e ampliação desses materiais para adequar-se as realidades nas quais ela será utilizada.

\section{CONSIDERAÇÕES FINAIS}

O processo de reflexão histórica que nos propomos a realizar não se esgota neste breve trabalho. Acreditamos que as discussões levantadas servem como uma introdução para um importante debate sobre o uso de campanhas sanitárias na Educação em Saúde. Na atualidade, conforme salientado no texto, as campanhas sanitárias Brasileiras parecem seguir, ainda, um modelo muito transmissional, sendo emergente refletir sobre este tipo de material compreendendo-o como parte do bojo educacional.

A Educação Popular em Saúde parece mostrar-se como uma ferramenta que pode auxiliar no combate a ideia de "culpabilização da vítima", presente nos convites para realização de mutirões e, portanto, resultar em um maior engajamento populacional no combate a doenças. É preciso fazer com que as campanhas sanitárias cheguem as periferias de uma forma diferente de um manual de regras, estabelecendo, nestes materiais, oportunidades de diálogo com a sociedade. 
Neste sentido, há um longo caminho a percorrer para pesquisar de forma mais profunda a utilização das campanhas sanitárias, tanto em ambientes formais como informais de Educação em Saúde, assim como analisar e discutir formas de superar os obstáculos que estes materiais enfrentam para chegar até a população em geral.

\section{REFERÊNCIAS}

ALMEIDA-JÚNIOR, João Baptista de. Alfabetização para leitura de imagens: apontamentos para uma pesquisa educacional, Revista de Educação da PUC-Campinas, n.8, p. 15-21, jun. 2000. Disponível em: https://seer.sis.puc-campinas.edu.br/seer/index.php/reveducacao/article/viewFile/412/392.

BRASIL. Ministério da Educação (MEC), Secretaria de Educação Média e Tecnológica (Semtec). PCN Ensino Médio: orientações educacionais complementares aos Parâmetros Curriculares Nacionais - Ciências da Natureza, Matemática e suas Tecnologias. Brasília: MEC/Semtec, 2002.

CHARAUDEAU, Patrick. Imagem, mídia e política: construção, efeitos de sentido, dramatização, ética. In.: MENDES, Emília (Coorda.); MACHADO, Ida Lucia; LIMA. Helcira; LYSARDO-DIAS, Dylia (Orgas.). Imagem e discurso. Belo Horizonte: FALE-UFMG, 2013. p. 383-405.

ESCOREL, Sarah. Mário Magalhães: desenvolvimento é saúde. Ciência \& Saúde Coletiva, v. 20, n. 8, p. 2453-2460, 2015. Disponível em: http://www.scielo.br/pdf/csc/v20n8/1413-8123-csc-20-08-2453.pdf.

FALKENBERG, Mirian Benites et al. Educação em saúde e educação na saúde: conceitos e implicações para a saúde coletiva. Ciência \& Saúde Coletiva, v. 19, n. 3, p. 847-852, 2014. Disponível em: http://www.scielo.br/scielo.php?script=sci_arttext\&pid=S1413-81232014000300847.

FREITAS, Fernanda Valéria de; REZENDE FILHO, Luiz Augusto. Modelos de comunicação e uso de impressos na educação em saúde: uma pesquisa bibliográfica. Interface - Comunicação, Saúde, Educação, v.15, n. 36, p. 24355, jan./mar. 2011. Disponível em: http://www.scielo.br/scielo.php?pid=S1414$\underline{32832011000100019 \& \text { script=sci_abstract\&tlng=pt }}$

GALVÃO, Marcio Antônio Moreira. Origem das Políticas de Saúde Pública no Brasil: do Brasil-colônia a 1930. Caderno de textos do departamento de ciências médicas da escola de farmácia da universidade federal de ouro preto, Ouro Preto, 2009.

JOLY, Martine. Introdução à análise da imagem. Campinas: Papirus, 1996

MACIEL, Marjorie Ester Dias. Educação em saúde: conceitos e propósitos. Cogitare Enfermagem, v. 14, n. 4, p. 773-776, out./dez. 2009. Disponível em: http://www.saude.ufpr.br/portal/revistacogitare/wpcontent/uploads/sites/28/2009/10/16399-56889-3-PB.pdf.

PELICIONI, Maria Cecília Focesi; PELICIONI, Andréa Focesi. Educação e promoção da saúde: uma retrospectiva histórica. O Mundo da Saúde São Paulo, v. 31, n. 3, p. 320-328, jul./set. 2007. Disponível em: http://www.saocamilo-sp.br/pdf/mundo_saude/55/02_restrospectiva_historica.pdf.

POLIGNANO, Marcos Vinícius. História das políticas de saúde no Brasil: uma pequena revisão. Cadernos do Internato Rural - textos de apoio, 2001. Disponível: http://medicinadeemergencia.org/wpcontent/uploads/2015/04/historia-das-politicas-de-saude-no-brasil-16-030112-SES-MT.pdf. Acesso em: 12 de setembro de 2018 . 
ROCHA, Sheila; FELTES, Heloisa Pedroso de Moraes. Multimodalidade da linguagem nas campanhas de prevenção HIV / Aids: uma análise cognitiva e cultural, Signo, v. 41, n. 70, p. 75-87, 2016. Disponível em: https://online.unisc.br/seer/index.php/signo/article/view/6396.

SALES, Fátima Maria de Souza. Ações de educação em saúde para prevenção e controle da dengue: um estudo em Icaraí, Caucaia, Ceará. Ciências e saúde coletiva, v. 13, n. 1, p. 175-184, 2008 Disponível em: http://www.scielo.br/scielo.php?pid=S1413-81232008000100022\&script=sci_abstract\&tlng=pt

SILVA, Cristiane Maria da Costa; MENEGHIM, Marcelo de Castro; PEREIRA, Antonio Carlos; MIALHE, Fábio Luiz. Educação em saúde: uma reflexão histórica de suas práticas. Ciência \& Saúde Coletiva, v. 15, n. 5, p. 2539-2550, 2010. Disponível em: http://www.scielo.br/scielo.php?pid=S1413$\underline{81232010000500028 \& \text { script }=\text { sci_abstract\&tlng=pt. }}$.

SOUZA, Kátia Reis de et al. o desenvolvimento compartilhado de impressos como estratégia de educação em saúde junto a trabalhadores de escolas da rede pública do Estado do Rio de Janeiro. Cad. Saúde Pública, Rio de Janeiro, v. 19, n. 2, p. 495-504, mar./abr. 2003. Disponível em: http://www.scielo.br/pdf/csp/v19n2/15415.pdf.

VALLA, Victor Vicent. Controle social ou controle público? In.: DE SETA, Marismary Horsth et al. (Orgs.). Gestão e vigilância sanitária: modos atuais de pensar e fazer. Rio de Janeiro: Editora Fiocruz, 2006. p. 49-60.

VASCONCELOS, Eymard Mourão. Educação popular e a atenção à saúde da família. 6. ed. São Paulo: Hucitec: 2015.

VASCONCELOS, Eymard Mourão. Redefinindo as práticas de saúde a partir da educação popular nos serviços de saúde. In.: VASCONCELOS, Eymard Mourão; PRADO, Ernande Valentin do. (Orgs.). A saúde nas palavras e nos gestos: reflexões da rede de educação popular e saúde. 2. ed. São Paulo: Hucitec, 2017. p. 19-33.

VASCONCELOS, Eymard Mourão. Redefinindo as práticas de Saúde a partir de experiências de Educação Popular nos serviços de saúde. Interface - Comunicação, Saúde, Educação, v. 5, n. 8, Botucatu, fev. 2001.

VIDAL, Carlos. Medicina comunitaria: nuevo enfoque de la medicina. Educ Med Salud, v. 9, n.1, p. 11-46, 1975.

\section{(cc) $\overline{E Y}$}

Este trabalho está licenciado com uma Licença Creative Commons - Atribuição 4.0 Internacional. 